\title{
ORGANIC THIN FILM PHOTOVOLTAIC DEVICES FROM DISCOTIC MATERIALS
}

\author{
Lukas Schmidt-Mende* \\ Cavendish Laboratory, University of Cambridge, \\ Madingley Road, Cambridge CB3 OHE, UK \\ Mark Watson and Klaus Müllen \\ Max-Planck-Institut für Polymerforschung, \\ Ackermannweg10, D-55128 Mainz, Germany \\ Richard H. Friend \\ Cavendish Laboratory, University of Cambridge, \\ Madingley Road, Cambridge CB3 OHE, UK
}

\begin{abstract}
Since the first demonstration of organic photovoltaic devices much progress has been made. Organic solar cells reach now power conversion efficiencies of up to $3 \%$ over the solar spectrum. The morphology of the active film is very important for efficient devices. Films spin-coated from blend solutions phase separate. The scale of the phase separation depends on the solvent, solubility of the materials and parameters of the spin-coating process such as speed, temperature, etc. If the morphology could be controlled on a molecular scale the efficiency of charge separation and transport could be expected to be substantially higher. The use of discotic liquid crystalline materials might help to reach this goal, because of their capacity to self-organise into columnar stacks.

In this work we describe photovoltaic devices made with discotic liquid crystalline hexabenzocoronene and perylene dye molecules. Thin films have been produced by spin coating blends directly from solution. Devices with an external quantum efficiency (incident photon to current efficiency) of up to $34 \%$ at monochromatic illumination at $490 \mathrm{~nm}$ have been achieved with a blend of

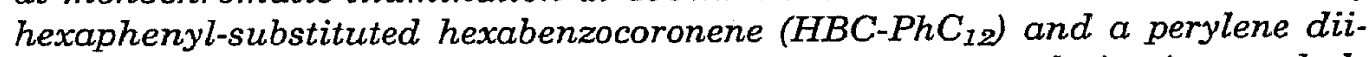
mide. Photovoltaic devices with other hexabenzocoronene derivatives as hole conductor show lower efficiencies. We attribute the lower device performance of the latter to the different film morphology occurring from spin coating of these materials.
\end{abstract}

The authors would like to thank the European Union for funding (DISCEL G5RD-CT-200000321). Partial funding was provided by Sony International (Europe).

"E-mail: ljs38@cam.ac.uk 
The aim of this work is to exploit the advantageous self-organising properties of HBC-perylene blends for solar cells.

Keywords: Organic solar cells; discotics; hexabenzocoronene

\section{INTRODUCTION}

Despite a lot of effort the cost of conventional semiconductor processing remains high. High-temperature and high vacuum steps are necessary for processing these serniconductors. As an alternative organic semiconducting materials are promising candidates. They have the advantage that they can be processed extremely cheaply over large areas at low temperatures by processing directly from solution. Fabrication of organic solar cells by screen-printing has been successfully demonstrated [1].

Organic semiconductors have many applications for electronic devices. With the discovery of electroluminescence in conjugated polymers [2], this class of materials has been used in light-emitting diodes (LEDs) [2-6], but also in field effect transistors [7-14], optically pumped lasers [15-19] and photovoltaic devices [20-28].

In this work application of discotic crystalline materials for organic photovoltaic devices will be described. The performance of the devices will be discussed with a special emphasis on device performance and film morphology.

\section{EXPERIMENTAL SECTION}

Blends were prepared by mixing the different solutions (concentration of $15-20 \mathrm{mg} / \mathrm{mL}$ in chloroform) in different ratios together. For most devices we used blends of $60 \%$ perylene and $40 \% \mathrm{HBC}$ (by weight) for the three different HBCs respectively. It turned out that this gives the most efficient devices. Films were then spin coated from chloroform solution with $1500 \mathrm{rpm}$ onto ITO coated substrates, that have been previously cleaned and oxygen-plasma treated. Spin coating was performed in nitrogen atmosphere. The film thickness for the devices is $\sim 100-120 \mathrm{~nm}$. On top of these films a $120 \mathrm{~nm}$ aluminium electrode was evaporated $(p<3$ $\left.10^{-6} \mathrm{mbar}\right)$. Current-voltage curves and photocurrents were measured in dark and under illumination by using a source measure unit (Keithley 237). Monochromatic illumination was provided by the output of a tungsten lamp dispersed by a single-grating monochromator (Bentham M300). Quantum efficiencies were calculated using a calibrated silicon photodiode in the sample holder position as reference. All measurements were carried out under vacuum $\left(\mathrm{p}<510^{-5} \mathrm{mbar}\right)$. 
The external quantum efficiency (EQE), the number of collected electrons under short circuit conditions divided by the number of incident photons, is calculated as $\mathrm{EQE}=\mathrm{I}_{\mathrm{SC}} /\left(\mathrm{e} \mathrm{N}_{0}\right)$, with $I_{S C}$ the short circuit photocurrent density, $e$ the elementary charge and $N_{o}$ the incident photons flux density. The incident photon flux density $N_{o}$ is found out by measuring the spectral response with the calibrated Si-diode as reference. The fill factor $F F$ is calculated as $F F=\max _{0<\mathrm{V}<\mathrm{V}_{\mathrm{OC}}}(\mathrm{I}(\mathrm{V}) * \mathrm{~V}) /\left(\mathrm{I}_{\mathrm{SC}} * \mathrm{~V}_{\mathrm{OC}}\right)$ with $I_{S C}$ the short circuit current and $V_{O C}$ the open circuit voltage. The fill factor describes the maximum output power of an illuminated photodiode.

Absorption spectra were measured with a UV-Vis spectrometer (Hewlett Packard 8453). Reflection losses were neglected for all measurements. An atomic force microscope (Digital Instruments 3100 Series) was used in tapping mode to record micrographs of the film surfaces.

\section{RESULTS AND DISCUSSION}

In organic photovoltaic devices these excitons created by the incident light undergo charge-separation and are subsequently transported to the electrodes and extracted as a photocurrent. By using a blend of two different materials with different ionisation potentials charge separation can be strongly favoured.

The fundamental principal is illustrated in Figure 1. The electron will be attracted by the material with the lower LUMO (lowest unoccupied molecular orbital) level and the hole by the material with the higher HOMO (highest occupied molecular orbital) level. In order to increase the fraction of excitons that finds its way to an interface and to make charge separation more favourable than recombination it is important that the length scale of the phase separation is smaller than the diffusion range of an exciton. Once the charges are separated it is important that they can find a direct percolation path to the electrodes and are not trapped in an island of material. Islands of materials can act as recombination centres and hinder efficient charge collection at the electrodes. An ideal organic photovoltaic device would have a large interfacial area with an interpenetrating network of the two different with a direct percolation path to the electrodes (Fig. 2A). In reality the film structure looks different. In blend films we usually find a phase separation, where the length scale of the separation strongly depends on materials/solvents and spin coating conditions. A schematic of a blend is given in Figure 2B.

Some materials have self-organising properties that influence the film morphology. This is the case for discotic materials that build up stacks. For photovoltaic devices it would be ideal to have stacks of these discotics perpendicular to the substrate (Fig. 3 ). This would give high charge carrier 


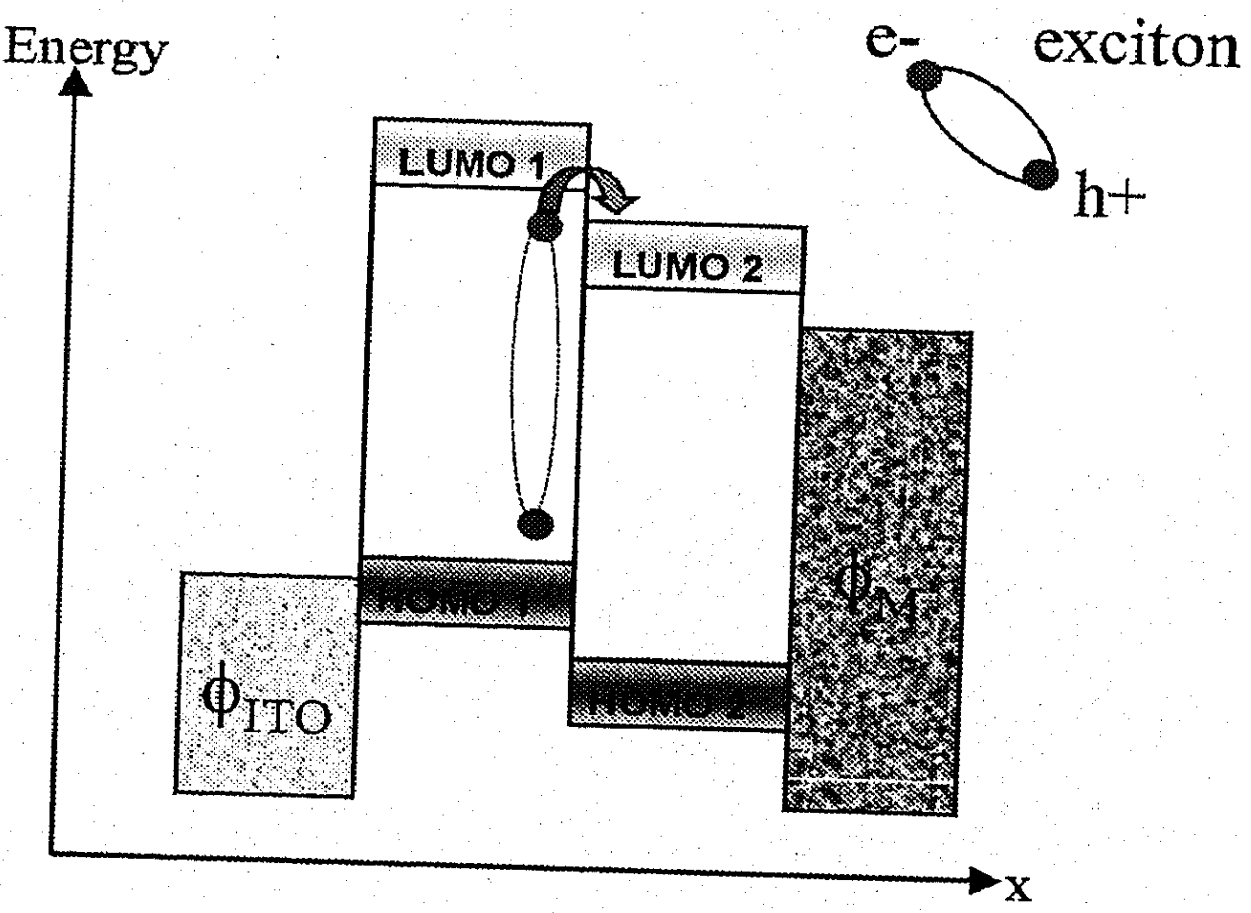

Hole Acceptor

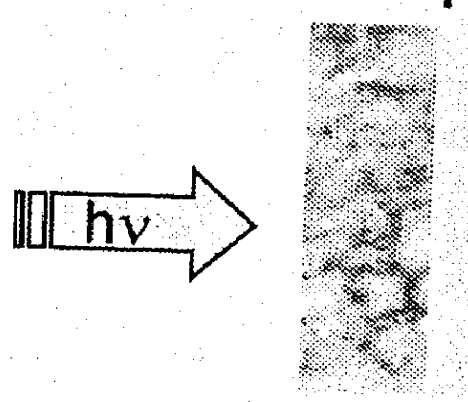

ITO

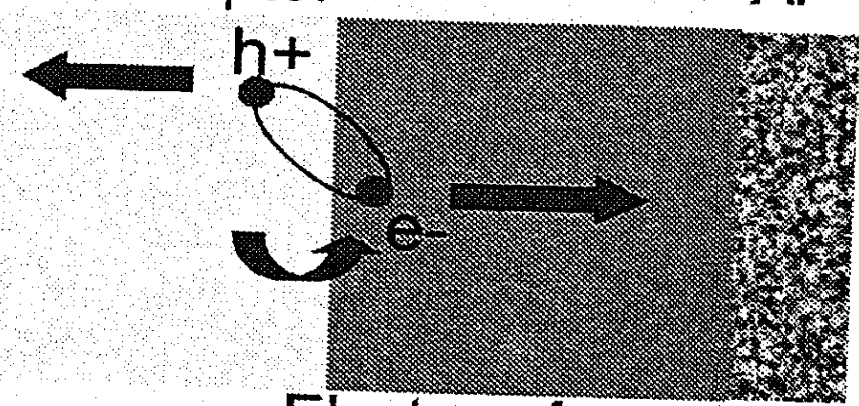

Electron Acceptor

FIGURE 1 Mlustration of the fundamental principal of an organic photodiode with two different organic materials with different electron affinities. If light reaches the interfacial area between the two organic materials, created excitons are separated and the charges are collected at the electrodes. (See Color Plate VI). mobility towards the electrodes and would avoid charge trapping and
recombination.

The chemical structures of the materials used in this work are shown in Figure 4.

\section{HBC-PhC 12}

In $\mathrm{HBC}-\mathrm{PhC}_{12}$ dodecyl side chains are coupled to the core via a paraphenylene moiety. This material is highly soluble. $\mathrm{HBC}-\mathrm{PhC}_{12}$ exists in a columnar liquid crystalline phase at room temperature. The cofacial 

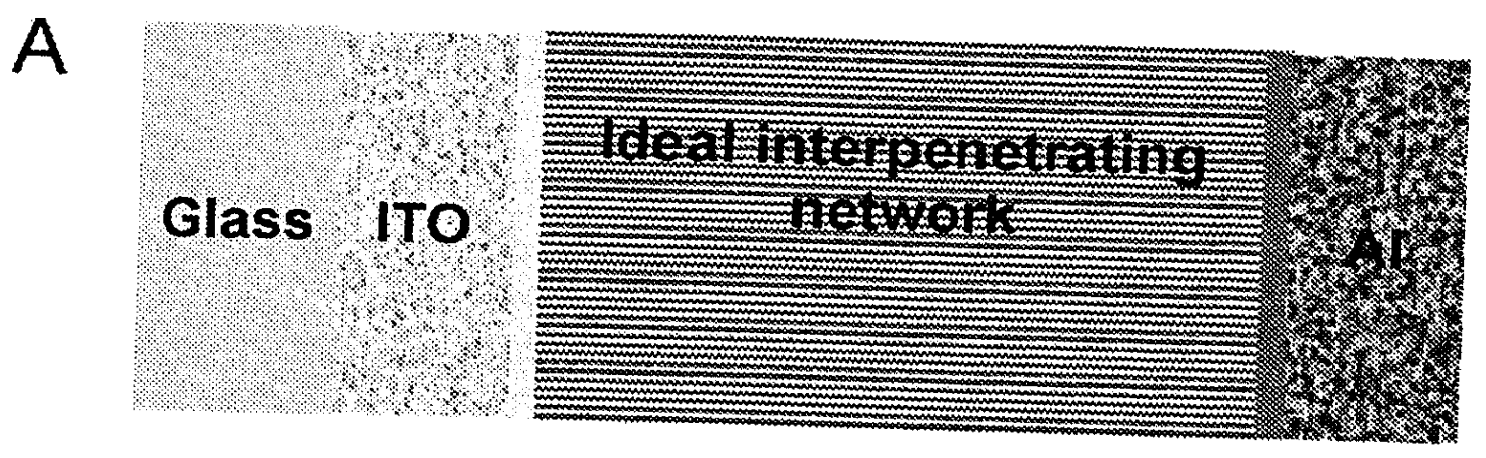

\section{Electron accepting polymer}

\section{Hole accepting polymer}

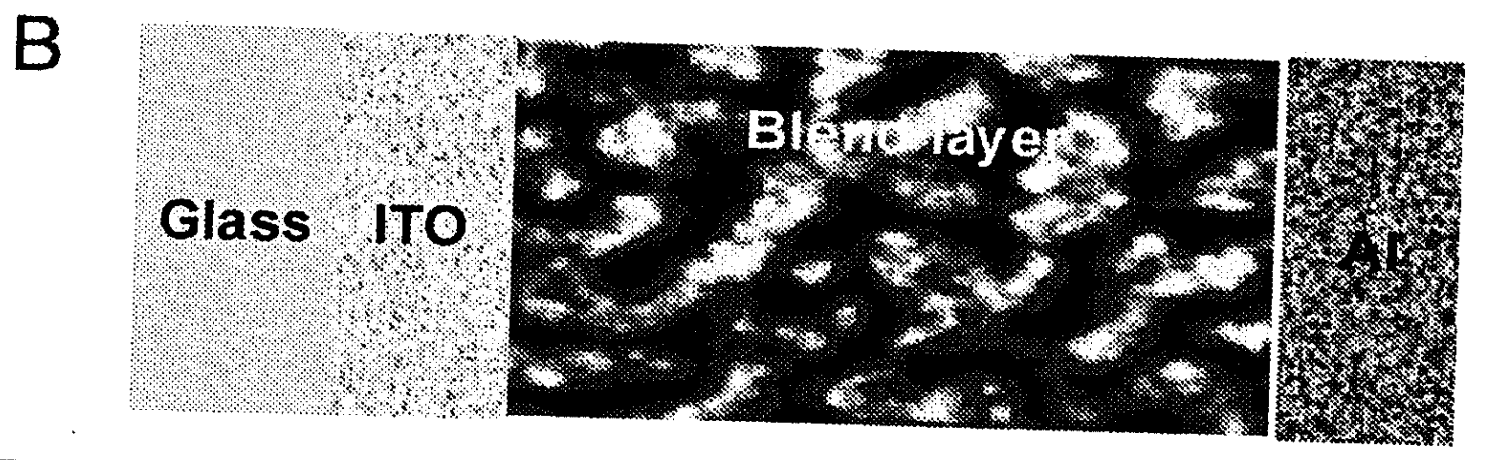

FIGURE 2 Schematic of an ideal blend devices structure (A) with a large interpenetrating network of the two different materials and a direct percolation path to the electrodes. This enables efficient charge separation and charge transport to the electrodes. (B) A schematic of a blend device. The scale of the phase separation of the different materials strongly depends on the spin-coating conditions. (See Color
Plate VID.
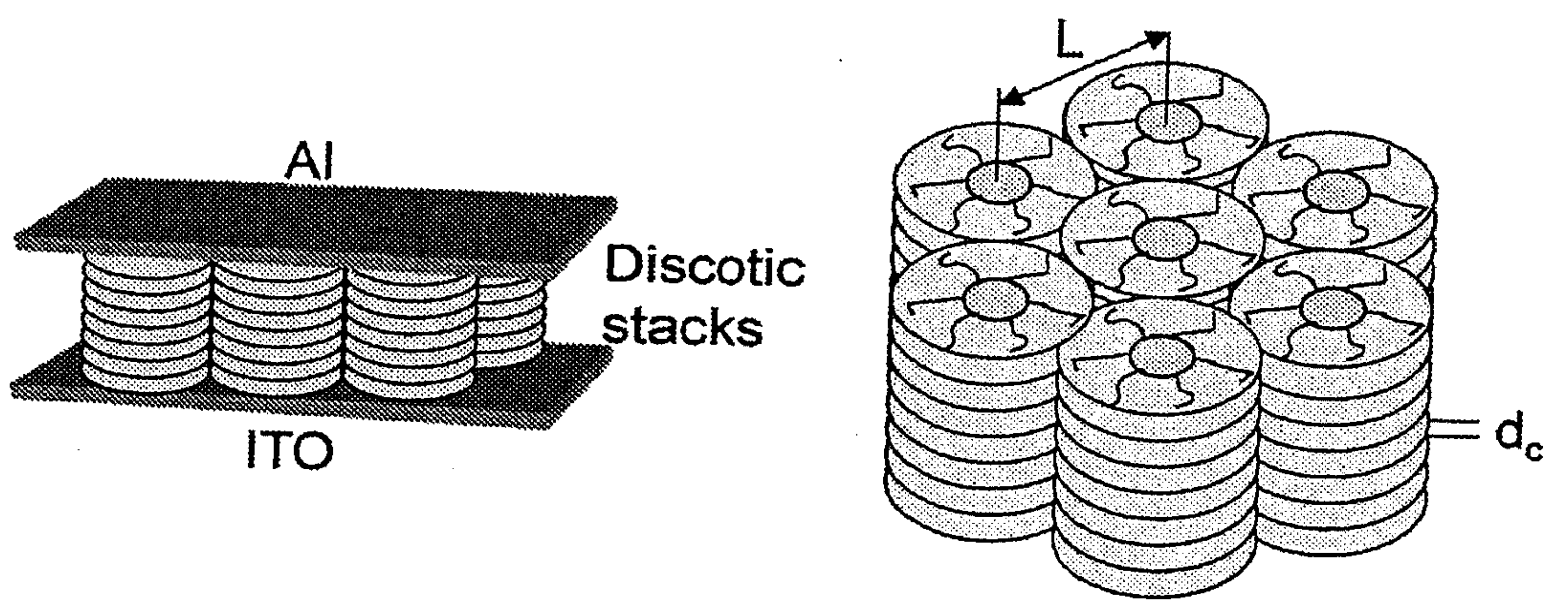

FIGURE 3 Ideal arrangement of the discotic stacks in a device configuration. The hexabenzocoronene stacks should be perpendicular to the surface substrate and be surrounded by the electron accepting perylene to get an ideal structure. 
A
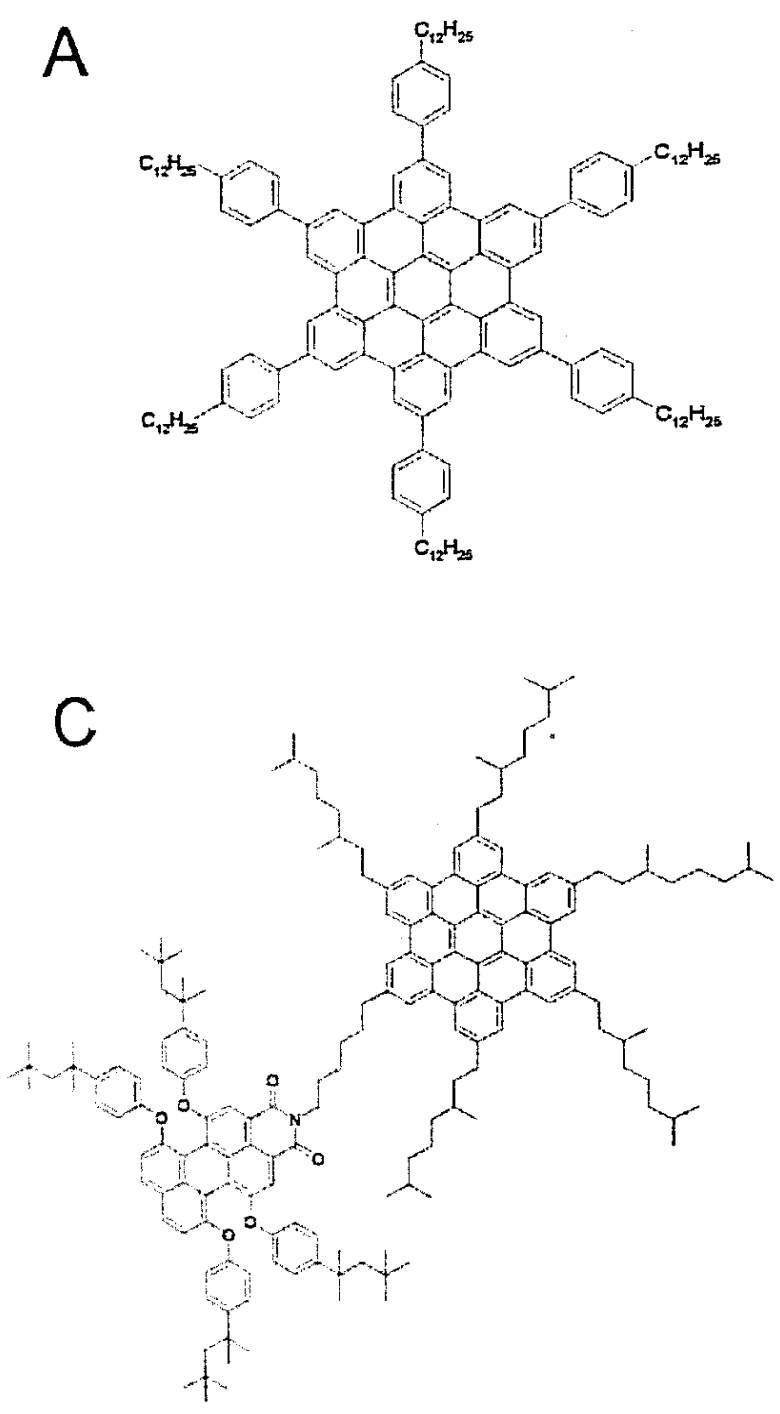

$E$

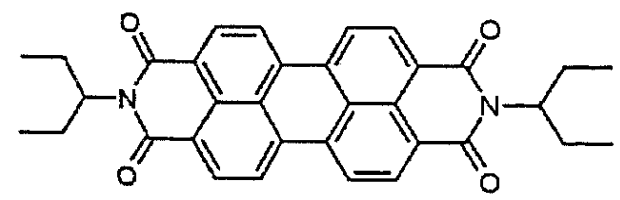

G

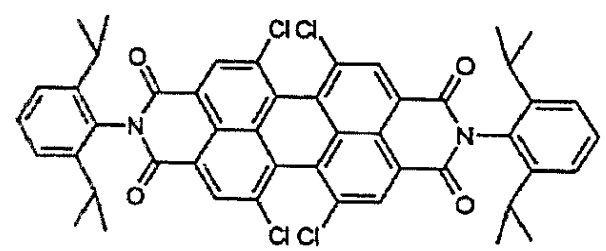

B
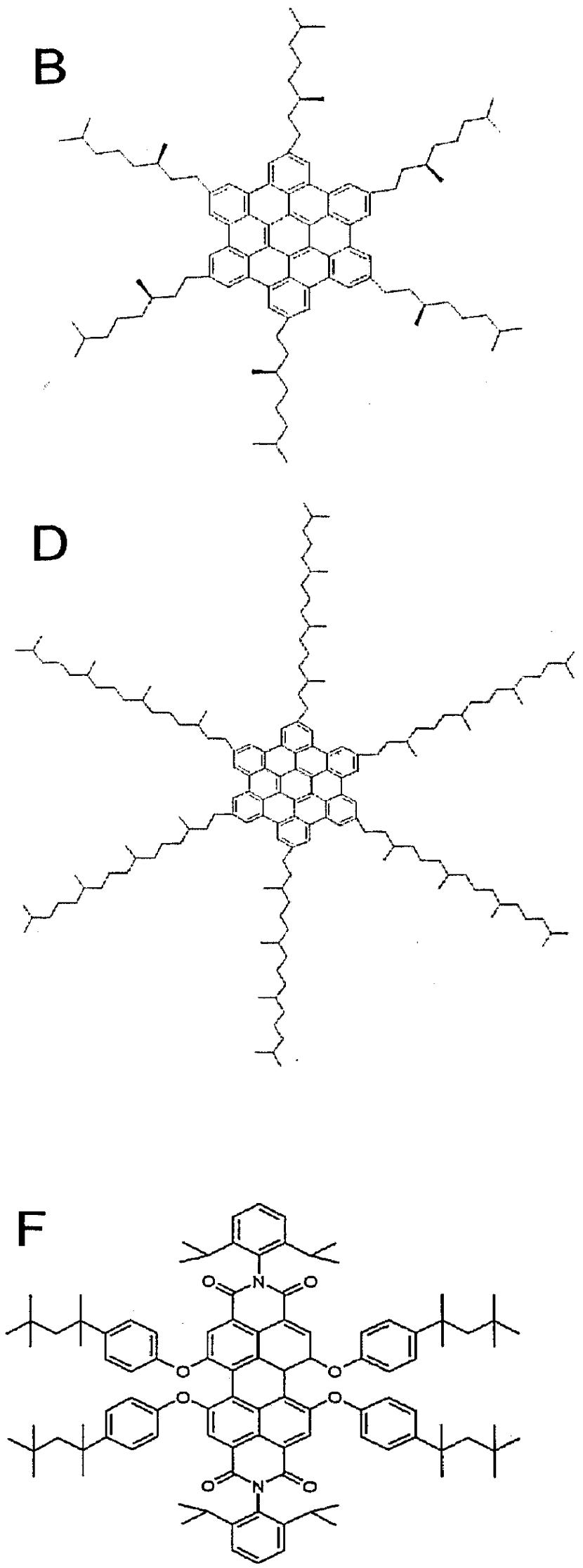

FIGURE 4 The different materials used in this work: (A) $\mathrm{HBC}^{-P_{1} \mathrm{C}_{12}}$, (B) HBC: $\mathrm{C}_{8}{ }^{*}$, (C) HBCperylene, (D) HBC-C $\mathrm{C}_{16}$, (E) EPPTC-perylene, (F) Tetraphenoxyperylene and (G) Tetrachloroperylene. 
distance is $d_{c}=3.5 \AA$ and the intercolumnar distance $L=34.0 \AA$. In pulseradiolysis time-resolved microwave conductivity (PR-TRMC) measurements $[29,30]$ the intracolumnar charge carrier mobilities were found to be as high as $\Sigma=0.22 \mathrm{~cm}^{2} \mathrm{~V}^{-1} \mathrm{~s}^{-1}$ at room temperature [31]. The PR-TRC method measures the charge carrier mobility on a nanometer length scale, so that traps caused by structural defects and impurities do not interfere with the mobility measurement. Therefore the mobilities measured with this method indicate an upper limit that could only be reached in a device made with an ideal film.

We blended this HBC compound with soluble perylene diimide (referred as EPPTC) (Fig. 4E). Perylene diimides are known to possess high electron mobilities [32] and have been utilised previously as an electron acceptor and transport material in dye/polymer devices [33].

High EQEs up to $34 \%$ could be achieved with the $\mathrm{HBC}-\mathrm{PhC}_{12}$ : EPPTC system (Fig. 5). The high values in this blend results from efficient photoinduced charge transfer between the hexabenzocoronene and perylene, as well as from effective transport of charges through the vertically segregated perylene and hexabenzocoronene $\pi$-systems. The open circuit voltage reaches $\mathrm{VOC} \sim 0.7 \mathrm{~V}$. A detailed description of the device performance and film morphology is given in [34]. It could be shown that in the

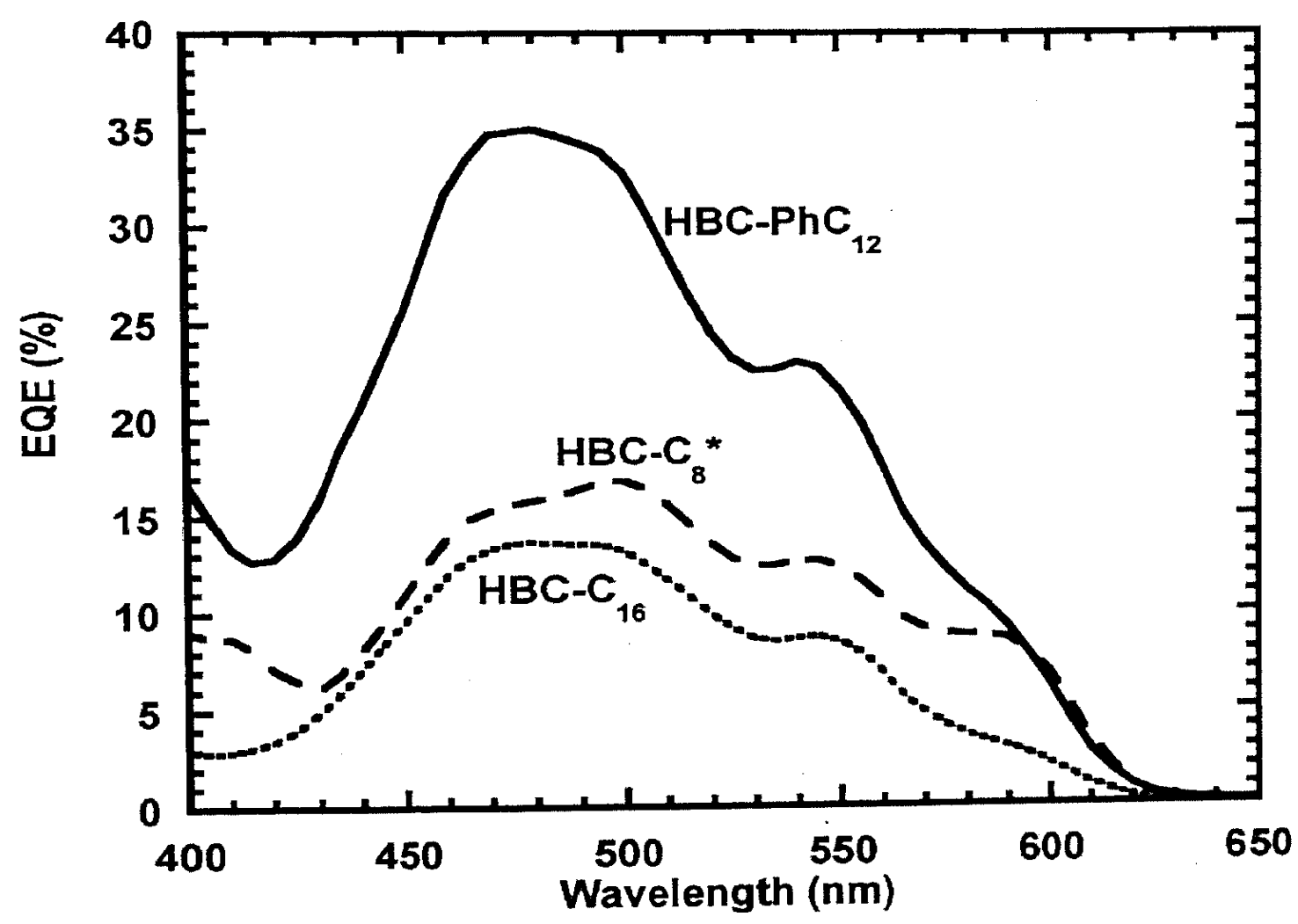

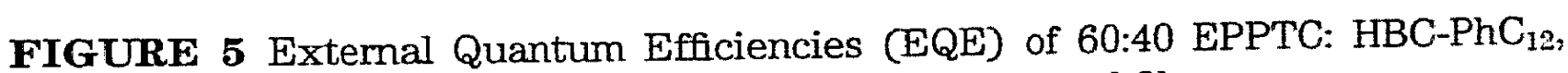
60:40 EPPTC: $\mathrm{HBC}_{-} \mathrm{C}_{8}{ }^{*}$ and 70:30 EPPTC-HBC- $\mathrm{C}_{16}$ blend films. 
spin-coating process a vertical segregation of the HBC and the perylene takes place that leads to a high interfacial area of both materials and at the same time a percolation path to the electrodes.

\section{HBCperylene}

The chemical structure of HBC-perylene is shown in Figure 4C. This material combines the electron accepting perylene with the hole accepting $\mathrm{HBC}$ in one molecule connected over a seven carbon bond bridge. Having both materials combined could improve the network formation of the materials and the ability to form stacks perpendicular to the surface. The idea is to use this material as a promoter for the network and stack forming in a blend together with perylene and HBC molecules.

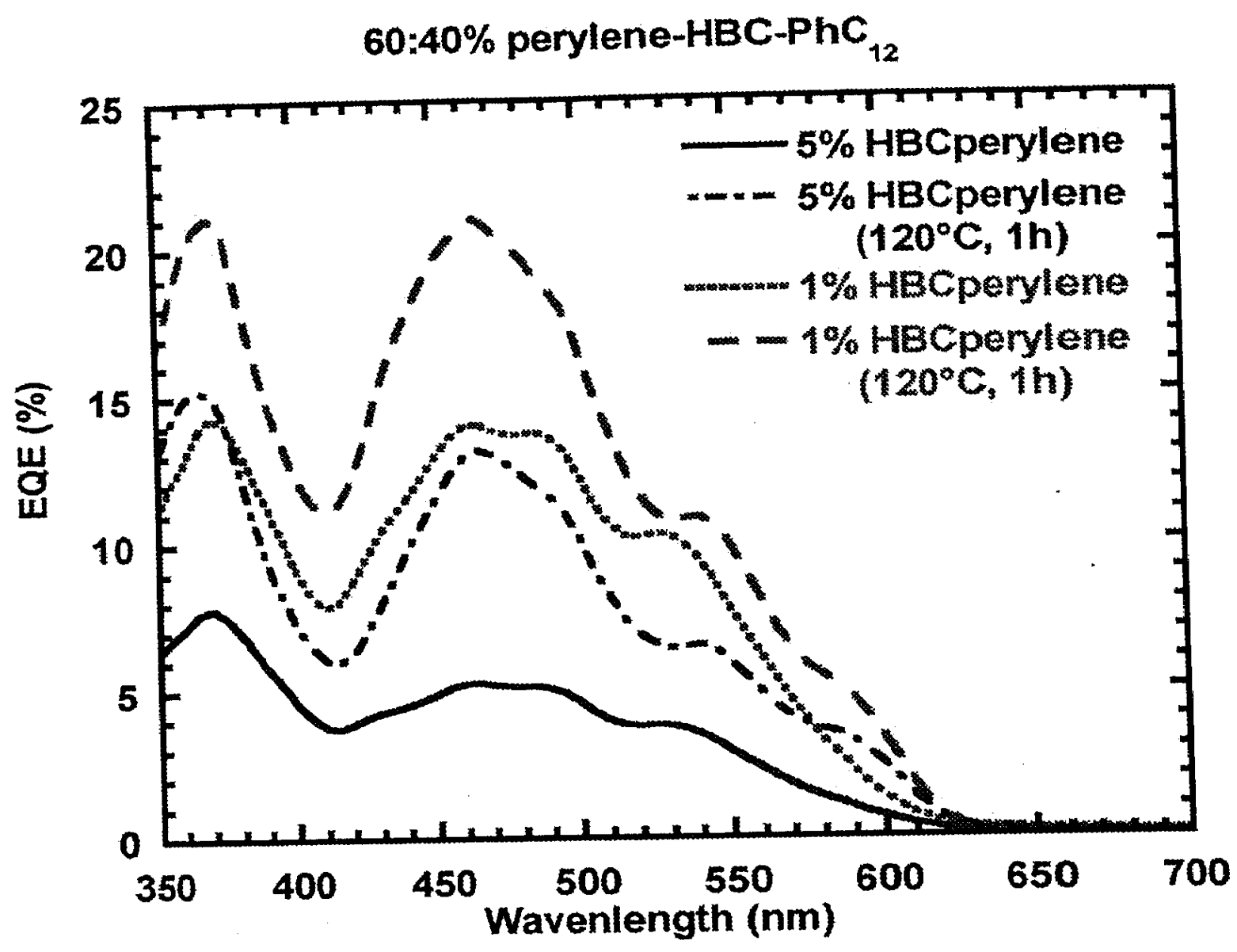

(A)

FIGURE 6 (A) $60: 40$ blend of EPPTC-HBC-PhC 12 with additional HBCperylene of $1 \%$ and $5 \%$ respectively and after annealing for an hour to $120^{\circ} \mathrm{C}$. (B) CurrentVoltage characteristic in dark (black) and under illumination (blue) of a HBCperylene film. The open circuit voltage is $\mathrm{VOC}=0.78 \mathrm{~V}$. (Inset on logarithmic scale). (See Color Plate VIII). 
HBCperylene

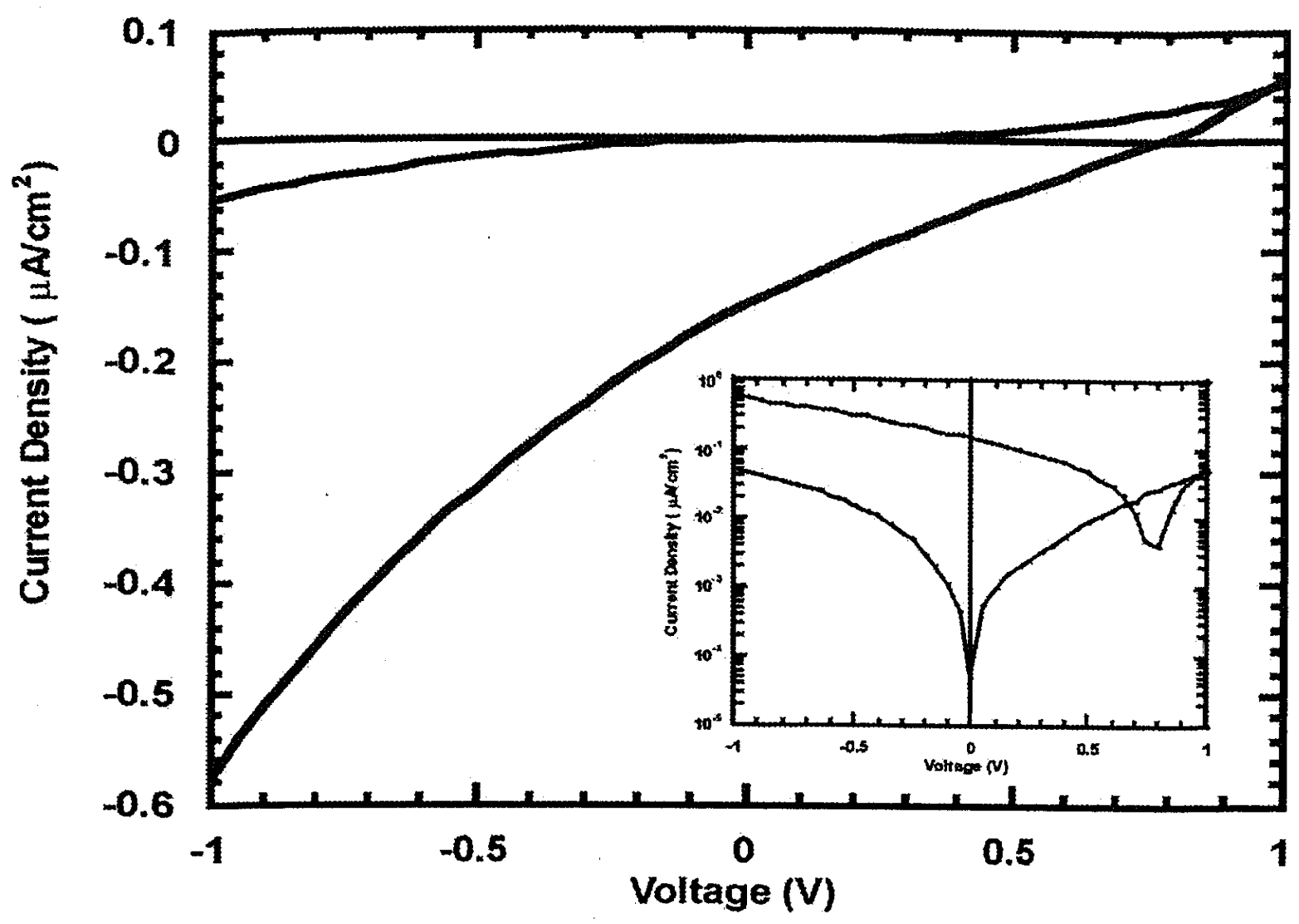

(B)

FIGURE 6 Continued. (See Color Plate IX).

In the pure HBCperylene device the EQE is low $(<0.1 \%)$. It follows closely the absorption of the HBCperylene. Efficient charge separation and/ or transfer over the HBCperylene system does not take place. The EQE drops down to lower efficiencies after annealing. The open circuit voltage is relatively high: $\mathrm{V}_{\mathrm{OC}}=0.78 \mathrm{~V}$, but the fill factor does not exceed $\mathrm{FF}=22.6 \%$ (Fig. 6B). 50-50\% perylene-HBC-perylene devices show even lower efficiencies of only just over $0.01 \%$. Then $1 \%$ and $5 \%$ of HBCperylene respectively were added to the solution of a $60 \%-40 \%$ blend of perylene and $\mathrm{HBC}_{-} \mathrm{PhC}_{12}$. The HBCperylene should promote the $\mathrm{HBC}-\mathrm{PhC}_{12}$ and perylene to build up an interpenetrating network with $\mathrm{HBC}-\mathrm{PhC}_{12}$ columns surrounded by perylene molecules.

In Figure 6 the EQE for the 60:40\% perylene-HBC- $\mathrm{PhC}_{12}$ blend devices with additional $1 \%$ and $5 \% \mathrm{HBCperylene}$ respectively are shown. Whereas for the $60: 40 \%$ perylene-HBC- $\mathrm{PhC}_{12}$ blend devices no annealing effects could be observed, the devices with the small percentage of HBCperylene improved significantly after annealing the film for one hour to $120^{\circ} \mathrm{C}$. This indicates a rearrangement of the molecules inside the film to a more favourable morphology for photovoltaic devices. 


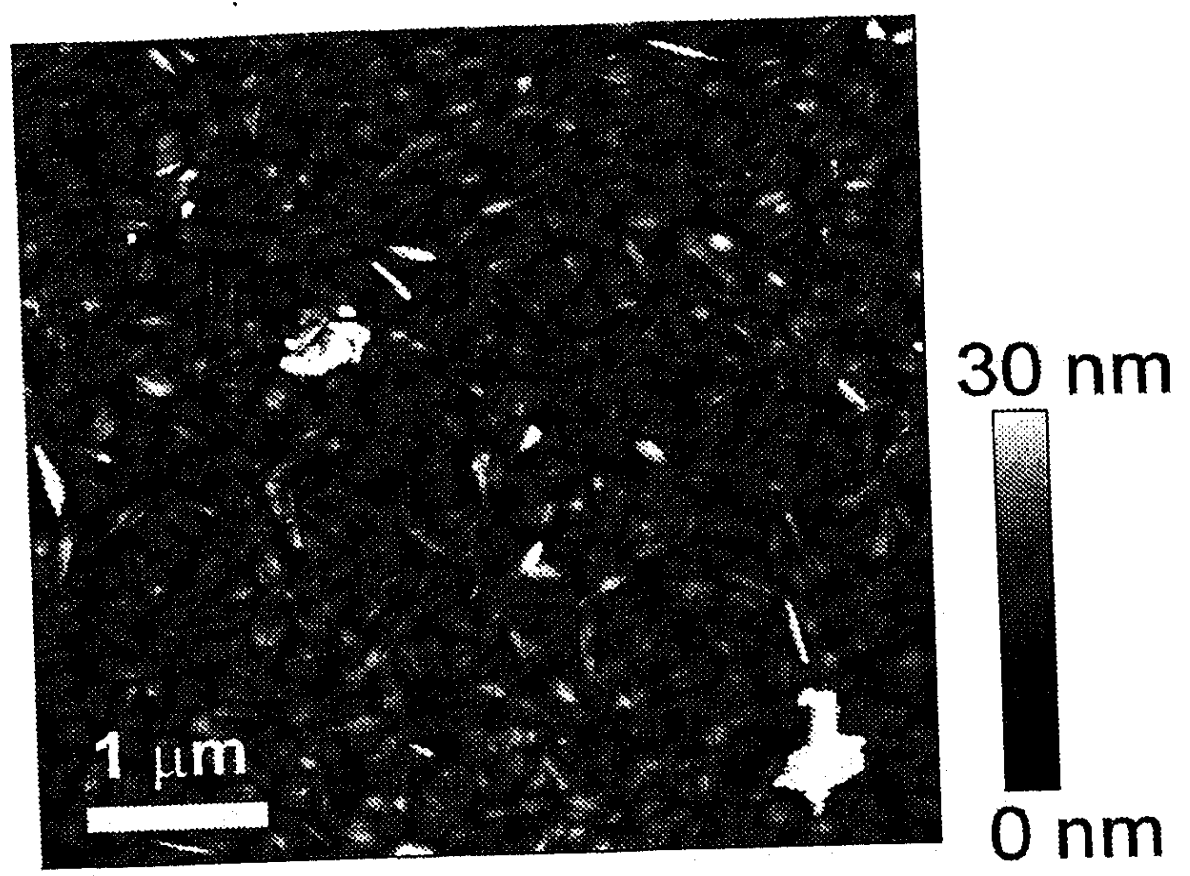

(A)

FIGURE 7 A) AFM-micrograph of a $60: 40$ blend of EPPTC-HBC-PhC 12 with additional $1 \%$ of HBCperylene. We attribute the sample crystallites, which can be seen on the surface of the film to the EPPTC-perylene. B) AFM micrograph of a 60:40 perylene:HBC- $\mathrm{C}_{16}$ blend film. Here the small crystallites typically observed in the EPPTC films cannot be observed. C) AFM micrograph of a 70:30 Tetraphenoxyperylene: $\mathrm{HBC}-\mathrm{PhC}_{12}$ film. No crystallization of the perylene can be observed on the surface structure of this film. (See Color Plate X).

Tapping mode AFM images of the film surface did not show a significant change after annealing. The surface of the blend which contains $1 \%$ HBCperylene is very similar to the pure blend (Fig. 7A). The typical needle like structure of the small perylene crystallites can be observed. These crystallites cover the whole surface. The film containing $5 \%$ of HBCperylene looks different. Here the sharpness of the needles is blurred out. This could be due to the fact that the perylene crystallites are not entirely on top of the film surface, but covered by $\mathrm{HBC}$ or HBCperylene molecules. This would explain the decrease in external quantum efficiency. The alrnost ideal structure of the HBC-perylene blend would be impaired with the additional HBCperylene.

It is assumed that the addition of HBCperylene does not support the interpenetrating network forming of electron acceptor and donor as desired. It does not seem to promote an ideal perylene-HBC network, which might be due to a twisting of the perylene compared to the $\mathrm{HBC}$ core in the comolecule. Also the distance between perylene and HBC might be too small, so that the $\mathrm{HBC}_{\mathrm{B}} \mathrm{PhC}_{12}$ and the perylene do not have enough space to 


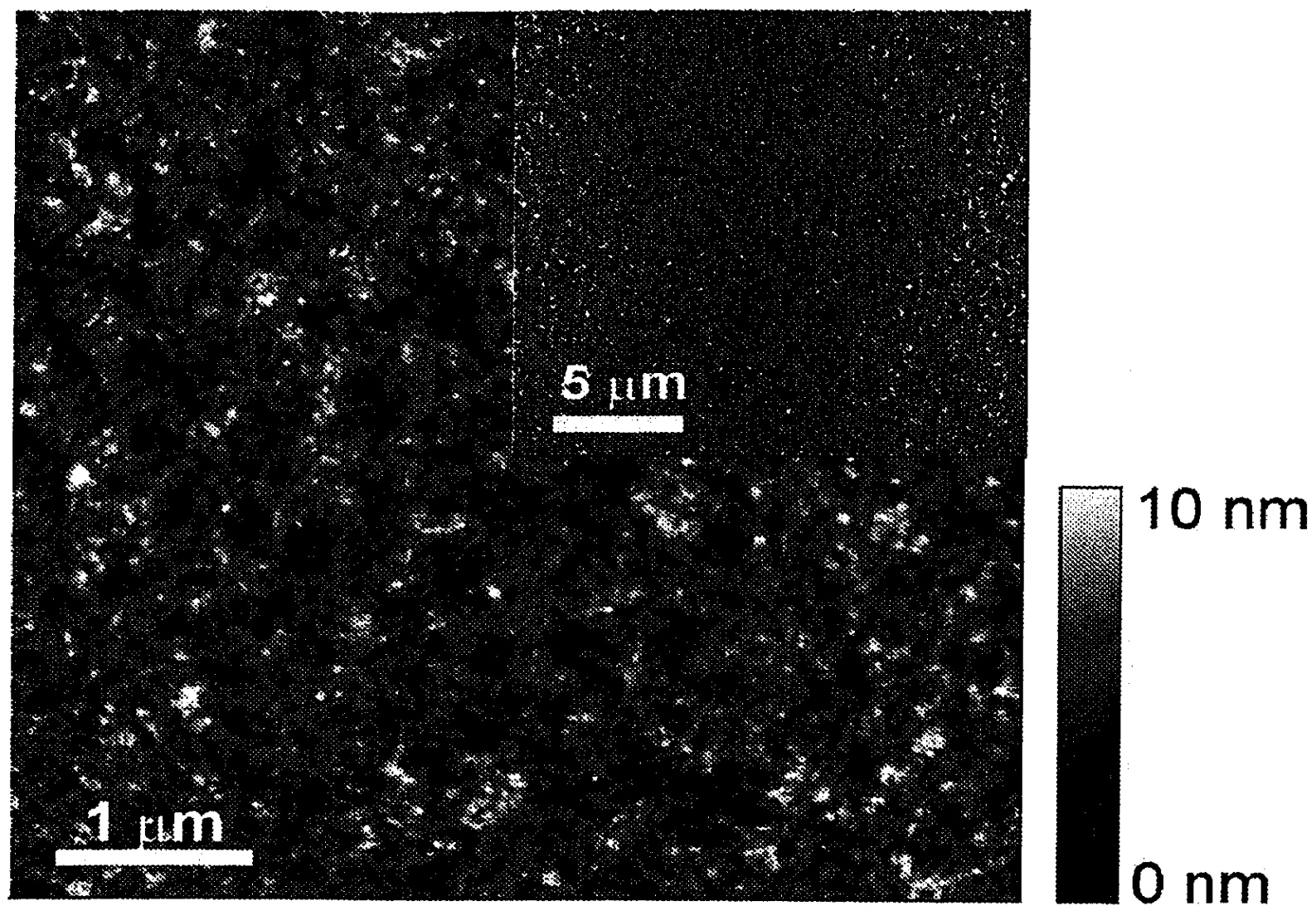

(B)

FIGURE 7 Continued. (See Color Plate XI).

arrange in the same matter as the HBCperylene, especially because of the phenyl- $\mathrm{C}_{12}$ chains that surround the HBC-core. Therefore a bigger distance between $\mathrm{HBC}$ and perylene might improve the device performance.

\section{HBC-C ${ }_{8} *$}

HBC-C8* is crystalline at room temperature. It is highly soluble in chloroform. It is extremely difficult to spin-coat smooth films of this material. The pure film of HBC-C8* spin-coated from chloroform solution is discontinuous and has deep holes almost through the entire film. The surface structure of blend films of HBC-C8* and perylene looks similar to the HBC-PhC12-perlyene blend films, except that the film is rougher. We see small crystallites that we attribute to the perylene.

The $\mathrm{EQE}$ is almost a factor of two higher for the $\mathrm{HBC}-\mathrm{PhC}_{12}$-perylene blend devices (Fig. 5). Also the open circuit voltage is lower in the HBC$\mathrm{C}_{8}{ }^{*}$ devices $(\mathrm{VOC} \sim 0.46 \mathrm{~V}$ ). These results suggest, that during the film formation process lyotropic LC effects are substantially different for the two HBCs. These results are discussed in more detail in Ref. [35]. 


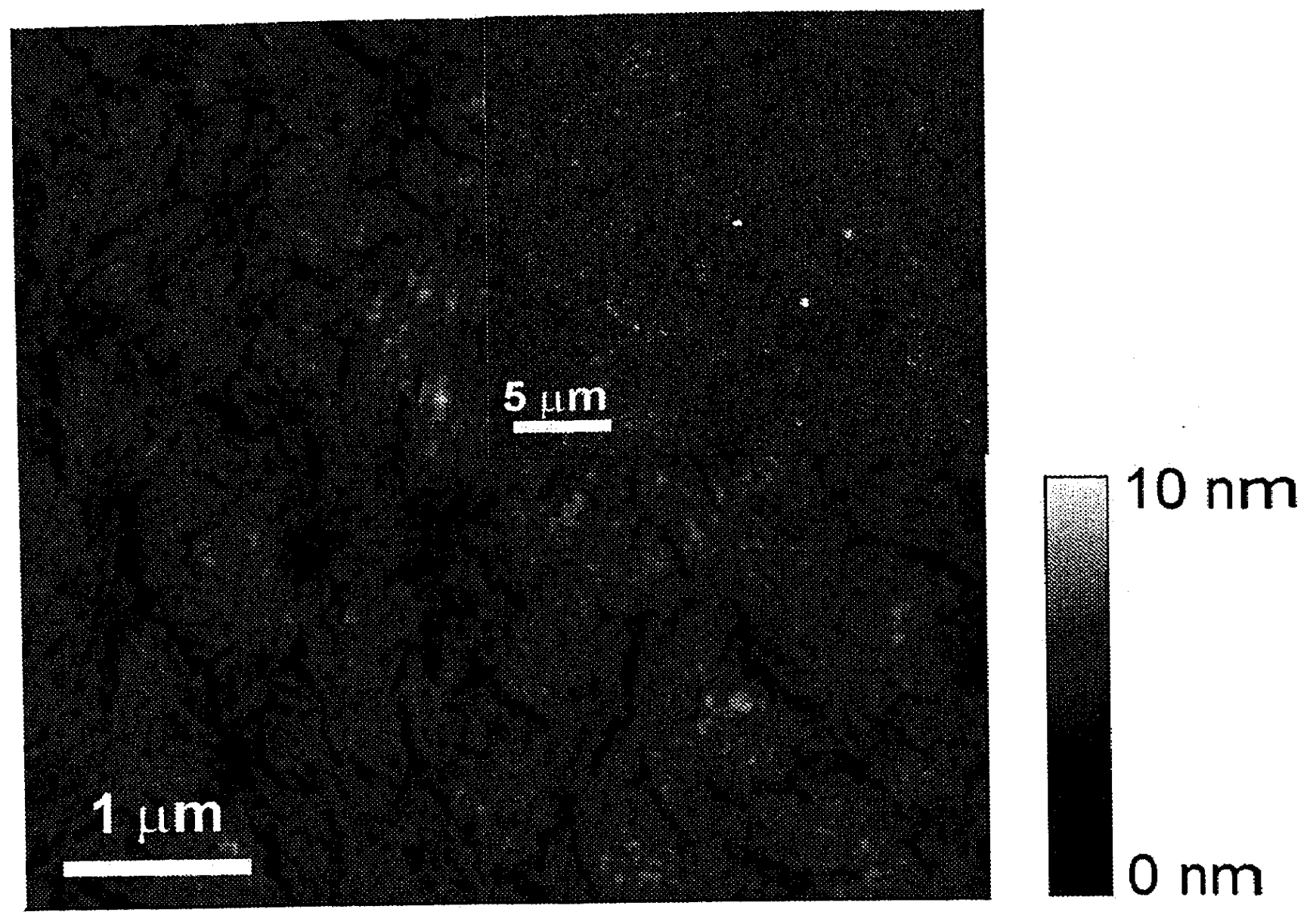

(C)

FIGURE 7 Continued. (See Color Plate XII).

\section{HBC-C 16}

HBC- $\mathrm{C}_{16}$ is a soft material that is liquid crystalline at room temperature and has a transition to the isotropic phase just above $230^{\circ} \mathrm{C}$. It seems to be advantageous for the film processing to have the material in the liquid crystalline phase. This is the motivation to use $\mathrm{HBC}-\mathrm{C}_{16}$. The chemical structure is shown in Figure $4 \mathrm{D}$. $\mathrm{HBC}-\mathrm{C}_{16}$ is highly soluble in chloroform. It forms very smooth films when spin coated from chloroform solution. This hexabenzocoronene was also blended together with the perylene described in Figure $4 \mathrm{E}$. The surface of the blend film is very smooth. The RMS roughness of the blend is $<1.7 \mathrm{~nm}$ and the peak to peak height does not exceed $20 \mathrm{~nm}$ (Fig. 7B). In the pure HBC-C ${ }_{16}$-film the RMS roughness is almost twice as much $(\sim 3 \mathrm{~nm})$ with peak to peak height of up to $30 \mathrm{~nm}$. The blend surface does not show the small crystallites that are typical for the perylene and were observed in the perylene-HBC-PhC $\mathrm{C}_{12}$ and $\mathrm{HBC}-\mathrm{C}_{8}{ }^{*}$ blends. The presence of the $\mathrm{HBC}-\mathrm{C}_{16}$ seems to prevent crystallisation of perylene into needle like structure. 
Different blend ratios of $\mathrm{HBC}-\mathrm{C}_{16}$ and perylene were tested. The highest external quantum effciency of almost 14\% was achieved for a $60: 40$ and a 70:30 blend of perylene:HBC- $\mathrm{C}_{16}$ (Fig. 5). Upon annealing a slight increase in the efficiency has been observed. The open circuit voltage of these devices is $\mathrm{V}_{\mathrm{OC}}=0.6 \mathrm{~V}$. The fill factor is $34.6 \%$. Due to the long aliphatic chain of 16 carbon atoms, a larger HBC-perylene separation distance is expected than for the $\mathrm{HBC}-\mathrm{C}_{8}{ }^{*}$, which is unfavourable for charge separation. The distance is slightly smaller than in the $\mathrm{HBC}-\mathrm{PhC}_{12}$ system, where the $\mathrm{HBC}$ stacks have an intercolumnar distance of $34 \AA$. But an improved efficiency compared to the $\mathrm{HBC}-\mathrm{PhC}_{12}$ devices could not be observed.

The results show again the high potential of hexabenzocoronenes. It usually has to be found a compromise between the chain-length and intercolumnar distance and separation distance between electron-acceptor and donor: The larger the side chains the lower the phase transitions (i.e. liquid crystalline phase already at room temperature) and the better the films. However, this has to be paid by a larger donor acceptor separation. Should one succeed in aligning the HBC stacks, then the high charge carrier mobility in stack direction could fully be exploited and higher effciencies can be expected.

\section{Other Perylene Derivatives as Electron Acceptors in $\mathrm{HBC}-\mathrm{PhC}_{12}$ blends}

Systems with other electron acceptor materials were investigated based on the promising result with the perylene:HBC-PhC $\mathrm{C}_{12}$ blend. The motivation for this replacement with other materials, such as other perylenes, is that they have their absorption peaks at longer wavelengths and match the solar spectrum better. Ideally our film should strongly absorb light over the entire sun-spectrum. The materials have to fulfil several physical and processing conditions:

- It is important that the materials have high charge carrier mobilities.

- The HOMO and LUMO levels of the materials have to be lower than the respective levels in $\mathrm{HBC}-\mathrm{PhC}_{12}$ to act as electron acceptor in the device.

- The absorption should be strong, preferably with a very broad peak, and must be in the visible region of the spectrum, preferably around $600 \mathrm{~nm}$.

- The material has to be soluble in common organic solvents. The solubility has to be high enough to enable spin coating of smooth thin films with the desired thickness of $\sim 100 \mathrm{~nm}$.

- It must also be possible to spin-coat smooth films from the blended solution with $\mathrm{HBC}-\mathrm{PhC}_{12}$. The spin-coated films should have the desired structure (phase separation on length-scale of exciton diffusion range, direct percolation path to the electrodes). 


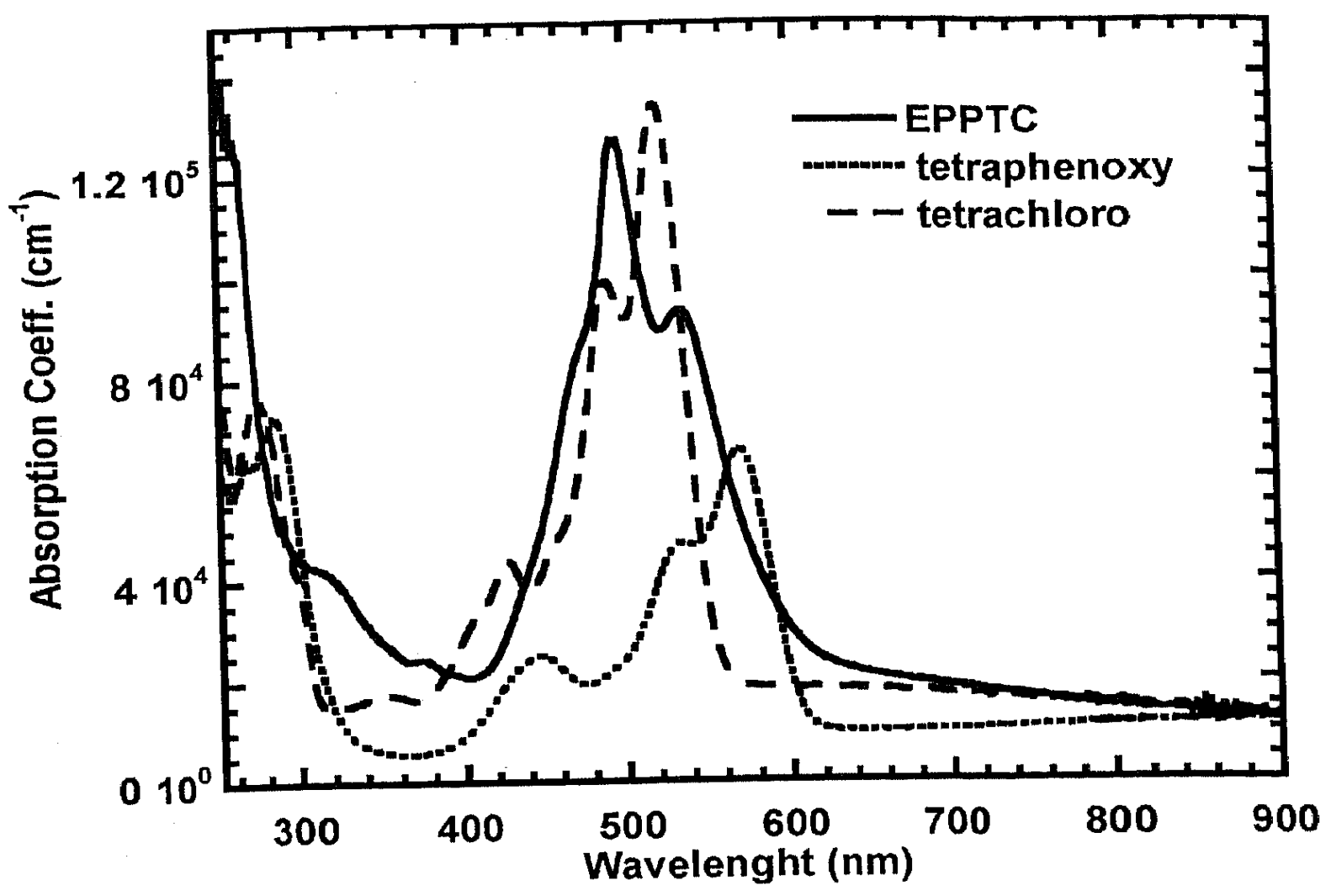

FIGURE 8 Absorption coefficient of thin films of EPPTC-perylene (solid line), Tetraphenox-perylene (dotted line) and Tetrachloro-perylene (dashed line).

The chemical structures of the different perylene derivatives used in the work described in this section are shown in Figure 4E-G.

The absorption coefficients of spin-coated thin films are shown in Figure 8. The tetraphenoxy-perylene has an absorption peak around $570 \mathrm{~nm}$, whereas the absorption peaks of the other perylenes are at shorter wavelengths. This makes the tetraphenoxy-perylene an interesting material for organic photovoltaic devices.

\section{RESULTS}

Different blend ratios from 10 to $90 \%$ (by weight) of the perylene derivative mixed with the $\mathrm{HBC}-\mathrm{PhC}_{12}$ have been investigated. Chloroform, xylene and THF were used as solvents. The solubility of all perylene derivatives is much higher in chloroform than in xylene. It was possible to dissolve the tetraphenoxy $(15 \mathrm{~g} / 1)$ in xylene at room temperature. However, to dissolve the other perylene derivatives the xylene solutions had to be heated to $120^{\circ} \mathrm{C}$. It was found that films from xylene solutions were much rougher than from chloroform solutions, especially with solutions containing EPPTC and tetrachloro-perylene. Most devices made from xylene solution were short circuit. The films are not homogeneous, this can be seen even 
without a microscope. The same problem occurred with the THF solution. It was not a problem to dissolve the tetraphenoxy or the tetrachloroperylene in THF, only the EPPTC-perylene solution needed annealing. But even with this clear solution the films spin-coated from it were rough. Higher HBC-Ph $\mathrm{C}_{12}$ content in THF solution leads to rougher films. It was only possible to make non short-circuit devices with the tetrachloroperylene-HBC-PhC 12 blends with more than $70 \%$ weight of tetrachloroperylene.

In the same batch, devices from tetraphenoxy, tetrachloro and EPPTCperylene:HBC-PhC ${ }_{12}$ solution were made. The EPPTC:HBC-PhC $\mathrm{E}_{12}$ were used as control devices. The control devices always showed a much higher efficiency than the devices with the other perylene derivatives.

The tetraphenoxy-perylene devices from chloroform solutions show always higher external quantum efficiencies than the devices from xylene solutions. The highest efficiency achieved with tetraphenoxy- and tetrachloro-perylene is shown in Figure 9A \& B. The maximum efficiency for the tetraphenoxy device is under $5 \%$ and the EQE-spectrum follows the

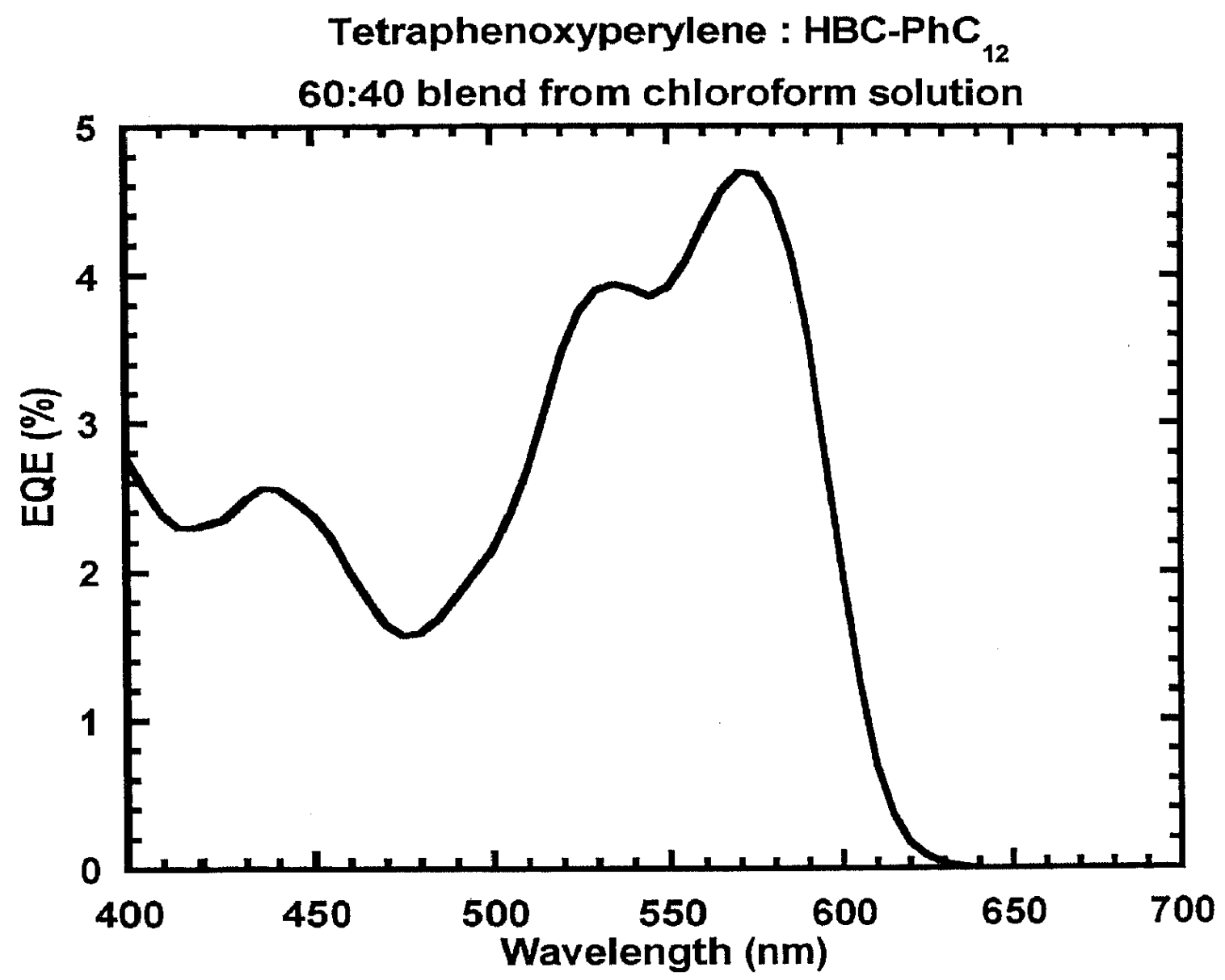

(A)

FIGURE 9 External Quantum Efficiencies (EQE) of (A) 60:40 Tetraphenoxyperylene: $\mathrm{HBC}-\mathrm{PhC} \mathrm{C}_{12}$ and (B) 30:70 Tetrachloro-perylene: $\mathrm{HBC}^{-\mathrm{PhC}_{12}}$ blend devices. 


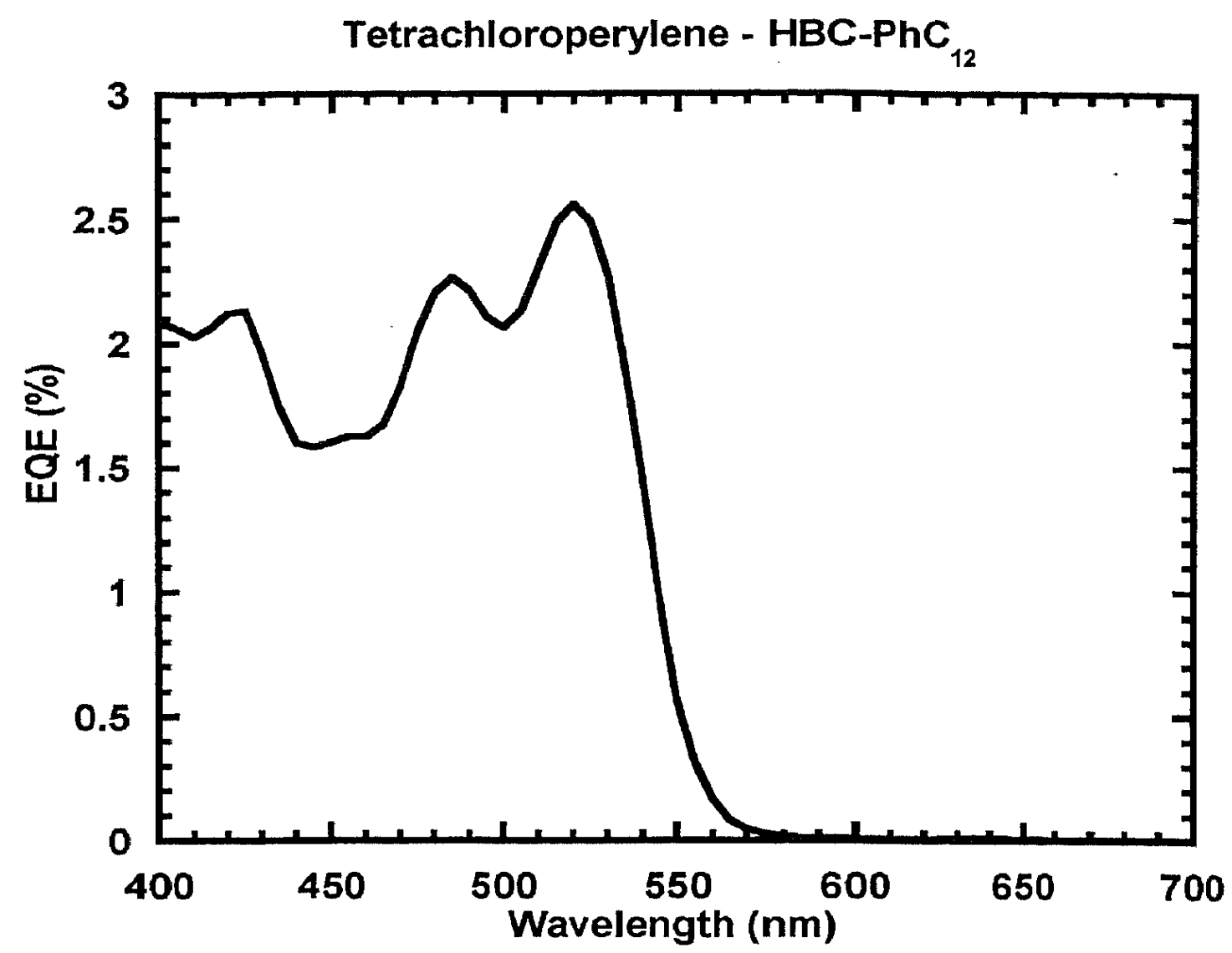

(B)

FIGURE 9 Continued.

absorption spectrum. The opencircuit voltage seems to be in the same range as for the EPPTC-HBC-PhC 12 devices around $\mathrm{V}_{\mathrm{OC}} \sim 0.6 \mathrm{~V}$.

The highest efficiency for the tetrachloro-device is just above $2 \%$. For these devices an open circuit voltage higher than $\sim 0.3 \mathrm{~V}$ was never achieved. This may indicate that in these films are highly conducting channels possibly due to pinholes where the Al could diffuse through the film, subsequently reducing the open circuit voltage.

The surface structure of a tetraphenoxy-blend film is shown in Figure 7 C. The film is quite smooth (RMS roughness of $\sim 1.1 \mathrm{~nm}$ and highest difference in height $\sim 10 \mathrm{~nm}$ ). The blend films with tetrachloro-perylene are much rougher (RMS roughness $\sim 6 \mathrm{~nm}$ with peak heights of over $50 \mathrm{~nm}$ ). For both systems no needle like structure can be observed at the film surface. This might be a reason why these devices are not as efficient as devices with the EPPTC-perylene. The small crystallites found on the latter seem to support efficient charge transport to the electrode.

The question arises, whether the main reasons for the lower efficiencies with other perylene derivatives are due to physical properties (such as charge carrier mobility, absorption coefficient) or whether only the optimal 
film spin-coating conditions leading to an optimal film morphology have not been found yet. Charge carrier mobility measurements, such as pulseradiolysis time-resolved microwave conductivity (PR-TRMC) measurements could help to answer this question.

\section{CONCLUSIONS}

HBC-PhC $\mathrm{P}_{12}$ is a very promising material for devices applications such as solar cells, because of its high charge carrier mobility, liquid crystallinity at room temperature and good solubility in organic solvents. Best results were achieved with this HBC compound. Films formed with other HBCs introduced in this work did not form the favourable morphology, which seems to be responsible for the lower photovoltaic performance in these devices.

The replacement of the EPPTC-perylene could have some advantages. Other dyes that absorb at longer wavelength would match the solar spectrum better and higher efficiencies over the solar spectrum could be expected. However the perylene derivatives used in this study blended with $\mathrm{HBC}-\mathrm{PhC}_{12}$ did not show the same devices performance. A maximum external quantum efficiency of $5 \%$ under monochromatic illumination has been achieved in devices made from tetraphenoxy-perylene.

\section{REFERENCES}

[1] Shaheen, S. E., Radspinner, R., Peyghambarian, N. \& Jabbour, G. E. (2001). Appl. Phys. Lett., 79(18), 2996.

[2] Burroughes, J. H., Bradley, D. D. C., Brown, A. R., Marks, R. N., Mackay, K., Friend, R. H., Burns, P. L. \& Holmes, A. B. (1990). Nature, 347(6293), 539.

[3] Braun, D. \& Heeger, A. J. (1991). Appl. Phys. Lett., 58(18), 1982.

[4] Greenham, N. C., Moratti, S. C., Bradley, D. D. C., Friend, R. H. \& Holmes, A. B. (1993). Nature, 365(6447), 628.

[5] Yang, Y., Pei, Q. \& Heeger, A. J. (1996). Jour. Appl. Phys., 79(2), 934.

[6] Tessler, N., Harrison, N. T. \& Friend, R. H. (1998). Adv. Mater., 10(1), 64.

[7] Garnier, F., Hajlaoui, R., Yassar, A. \& Srivastava, P. (1994). Science, 265(5179), 1684.

[8] Yang, Y. \& Heeger, A. J. (1994). Nature, 372(6504), 344.

[9] Brown, A. R., Pomp, A., Hart, C. M. \& Deleeuw, D. M. (1995). Science, 270(5238), 972.

[10] Horowitz, G. (1998). Adv. Mater., 10(5), 365.

[11] Dodabalapur, A., Bao, Z., Makhija, A., Laquindanum, J. G., Raju, V. R., Feng, Y., Katz, H. E. \& Rogers, J. Appl. Phys. Lett., 73(2), 142.

[12] Sirringhaus, H., Tessler, H. N. \& Friend, R. H. (1998). Science, 280, 1741.

[13] Kawase, T., Sirringhaus, H., Friend, R. H. \& Shimoda, T. (2001). Adv. Mater., 13(21), 1602.

[14] Kraft, A. (2001). Chem. Phys. Chem., 2(3), 163.

[15] Tessler, N., Denton, G. J. \& Friend, R. H. (1996). Nature, 382(6593), 695.

[16] Hide, F., Schwartz, B. J., Diaz-Garcia, M. A. \& Heeger, A. J. (1997). Synthetic Metals, $91(1-3), 35$. 
[17] McGehee, M. D., Diaz-Garcia, M. A., Hide, F., Gupta, R., Miller, E.K., Moses, D. \& Heeger, A. J. (1998). Appl. Phys. Lett., 72(13), 1536.

[18] Tessler, N., Ho, P. K. H., Cleave, V., Pinner, D. J., Friend, R. H., Yahioglu, G., Le Barny, P., Gray, J., de Souza, M. \& Rumbles, G. (2000). Thin Solid Films, 363, 64.

[19] Moll, N., Mahrt, R. F., Bauer, C., Schnable, B., Kley, E. B. \& Scherf, U., (2002). Appl. Phys. Lett., 80(5), 734.

[20] Wöhrle, D. \& Meissner, D. (1991). Adv. Mater, 3(3), 131.

[21] Halls, J. J. M., Walsh, C. A., Greenham, N. C., Marseglia, E. A., Friend, R. H., Moratti, S. C. \& Holmes, A. B. (1995). Nature, 376(6540), 498.

[22] Yu, G., Gao, J., Hummelen, J. C., Wudl, F. \& Heeger, A. J. (1995). Science, 270(5243), 1789.

[23] Roman, L. S., Andersson, M. R., Yohannes, T. \& Inganäs, O. (1997). Adv. Mater., 9(15), 1164.

[24] Roman, L. S., Mammo, L., Pettersson, A. A., Andersson, M. R. \& Inganäs, O. (1998). Adv. Mater., 10, 774.

[25] Granström, M., Petrisch, K., Arias, A. C., Lux, A., Andersson, M. R. \& Friend, R. H. (1998). Nature, 395, 257.

[26] Brabec, C. J. \& Sariciftci, N. S. (2000). In: Semiconducting Polymers, Hadziioannou, G. \& van Hutten, P. F. (Eds.), Wiley-VCH, Weinheim.

[27] Brabec, C. J., Sariciftci, N. S. \& Hummelen, J. C. (2001). Adv. Funct. Mater., 11(1), 15.

[28] Halls, J. J. M. \& Friend, R. H. (2001). In: Clean Electricity From Photovoltaics, Archer, M. D. \& Hill, R. (Eds.), Imperial College Press, London, 844.

[29] Adam, D., Closs, F., Frey, T., Funhoff, D., Haarer, D., Ringsdorf, H., Schuhmacher, P. \& Siemensmeyer, K. (1993). Phys. Rev. Lett., 70(4), 457.

[30] Schouten, P. G., Warman, J. M., de Haas, M. P., van Nostrum, C. F., Geliack, G. H., Nolte, R. J. M., Copyn, M. J., Zwikker, J. W., Engel, M. K., Hannack, M., Chang, Y. H. \& Ford, W. T. (1994). J. Am. Chem. Soc., 116, 6880.

[31] van de Craats, A. M., Warman, J. M., Fechtenkötter, A., Brand, J. D., Harbison, M. A. \& Müllen, K. (1999). Adv. Mater.., 11(17), 1469.

[32] Struijk, C. W., Sieval, A. B., Dakhorst, J. E. J., van Dijk, M., Kimkes, P., Koehorst, R. B. M., Donker, H., Schaafsma, T., Picken, S. J., van de Craats, A. M., Warman, J. M., Zuilhof, H. \& Sudhölter, E. J. R. (2000). J. Am. Chem. Soc., 122, 11057.

[33] Dittmer, J. J., Lazzaroni, R., Leclère, Ph , Moretti, P., Granström, M., Petrisch, K., Marseglia, E. A., Friend, R. H., Brédas, J. L., Rost, H. \& Holmes, A. B. (2000). Solar Energy Materials \& Solar Cells, 61, 53.

[34] Schmidt-Mende, L., Fechtenkötter, A., Müllen, K., Moons, E., Friend, R. H. \& MacKenzie, J. D. (2001). Science, 293, 1119.

[35] Schmidt-Mende, L., Fechtenkötter, A., Müllen, K., Friend, R. H. \& MacKenzie, J. D. (2002) Physica E, 14, 263. 